Article

\title{
Promoting Arabic Literacy in Primary Schools in the United Arab Emirates through the Emirati Dialect
}

\author{
Jean Pierre Ribeiro Daquila ${ }^{1,2}$ (D) \\ 1 ESERP Business and Law School, 08010 Barcelona, Spain; jeanpier@ucm.es or prof.jpdaquila@eserp.com \\ 2 Department of Applied Linguistics, Faculty of Philology, University Complutense of Madrid, \\ 28040 Madrid, Spain
}

Received: 28 September 2020; Accepted: 15 December 2020; Published: 18 December 2020

\begin{abstract}
Globalization has had an impact on the education system in the UAE, where the increased use of bilingual curriculum (Arabic-English) is held in high regard. Nevertheless, literacy in Arabic among Emirati children and teenagers remains low. This study uses a 15-item, open-ended questionnaire completed by Emirati parents and an eight-item, open-ended questionnaire completed by Emirati primary school children from 8 to 11 years of age to compare the translations of The Little Prince into Modern Standard Arabic (MSA) and into the Emirati dialect. The results suggest that not only the Emirati dialect, but any Arabic dialect (in its respective Arab country) could be used in primary schools to motivate children to read in Arabic and bridge the gap between their spoken language (dialect) and formal written Arabic. Not only must an Arab child learn how to read, but also, they have to understand a very formal language system that they are not used to speaking at home, i.e., Modern Standard Arabic (MSA). Having books in their own dialects may make children more interested in reading, as they can understand them more easily.
\end{abstract}

Keywords: translation; children literacy; fostering reading; Arab countries; MSA or dialect; UAE; primary schools

\section{Introduction}

The United Arab Emirates (UAE) were constituted in 1971 after oil was found in the region, which led to massive immigration, mainly to Dubai and Abu Dhabi, where more than $89 \%$ of the current population is foreign-born [1-3]. A need for international schools was clear, and English started being used in most public places and services, such as bars, movie theaters, taxis and gas stations, where often Arabic is not spoken by the staff at all. In the Emirates, mainly in the two aforementioned big cities, Emiratis need to understand English if they want to eat out in most restaurants, if they need information in a shopping mall or when they are shopping in a grocery store, as more than $89 \%$ of the population is constituted of non-Arabs [1-3]. In an attempt to be served in Arabic at The Dubai Mall, we visited 15 different restaurants and fast-food restaurants in January 2020; only three of these restaurants were employing waiters-one each in two establishments and two in the third restaurant-who spoke Arabic. None was an Emirati; one was from Morocco and two were from Egypt. How can an Emirati order in the other 12 establishments? Either in English or through gestures.

In order to compete in a globalized world, the UAE government has invested heavily in the education system, changing from instruction in Arabic to a bilingual curriculum where Arabic and English share the same importance [4]. In public schools, since the 1990s, English lessons begin in the first year of primary education [5].

Furthermore, Arab parents prefer sending their children to private schools [6-9], and most of these treat English as the standard, with British- or American-based curricula. This shift from public, free-of-charge Arabic schools to private schools has had a negative effect on young Emiratis' view of 
Modern Standard Arabic (MSA), as Arabic is no longer in the foreground of education. The reason why many parents are sending their children to private schools is to ensure that they can attain the TOEFL or the IELTS score required by Emirati universities [10]. Al-Hussein and Gitsaki [11] pointed out that this shift is also due to social status. In the UAE, MSA is only present in religious contexts, in the news (but not in local TV programs) and in textbooks at school, when these books are not written in English. MSA is first encountered in primary school and can be viewed almost as a second language [12]. Therefore, Arab children's first language is the spoken dialect, in the case of our study, the Emirati dialect. The linguistic distance between MSA and the child's spoken dialect was found to interfere directly and consistently with the acquisition of language, metalinguistic skills and reading in MSA among young Arabic native speaking children, as well as adolescents [12-15].

There is a lack of motivation among students regarding reading in the Emirates and the Arabic World in general. Presently, Arabic students around the globe prefer to read in English or French rather than in Arabic [16-19]. A survey carried out by Al-hussien and Belhiah [17] involving students ranging from 12 to 17 years of age, their parents and teachers, revealed that these students use mostly their dialect to communicate at home with family members and among their Emirati friends, while 98\% prefer to use English when using the internet. Also, 85\% prefer to read in English in lieu of MSA. These figures are alarming and led us to carry out this study in order to foster reading before secondary school. For Emirati students to enjoy reading in their own language in the first years of school, we need to keep in mind that the language they speak is the Emirati dialect, not MSA. Interestingly, $92.2 \%$ of parents and $100 \%$ of the teachers agreed with these figures. Some teachers said that students were only interested in reading books in English. They believed that their students lacked knowledge of Arab writers and literature. On the other hand, the students linked their preference to read and write in English with their daily exposure to English through the English curriculum, and to the fact that they were encouraged to use English at all times. The enormous need of English in daily life, its prestige in the UAE, and the sparse Emirati population are indications of a language shift, as proposed by Fasold [20], i.e., English has been replacing Arabic (this language shift will be analyzed in detail in the following section).

Therefore, we propose the use of books in the primary schools in the dialect of each Arabic country, because children speak in dialect; it is their first language (L1), and they do not have active contact with MSA. In other words, Arabic children never speak MSA, they only listen to it passively when they watch cartoons (many cartoons are in the dialect), read books at school or when they are in contact with religious texts or prayers. Having books written in the language that the child speaks (i.e., his or her dialect), in the language in which he/she interacts with friends and even with the teacher, might increase children's self-confidence and interest in reading. Reading in a language that is only passively received complicates understanding and may reduce students' motivation. If students first learnt to read in their L1, and then MSA was gradually introduced, they would feel more comfortable and motivated to read, as they would be reading something meaningful and within their own linguistic realm.

To determine whether children's interest in reading increases when reading in the dialect, and in an attempt to mitigate the aforementioned language shift, we interviewed Emirati parents and children who were shown two versions of The Little Prince: one in MSA and the other in the Emirati dialect. The research question for this study was: Do children express more interest in reading the version in the Emirati dialect, as it is their L1, in contrast to the MSA version that is learnt at a later stage, i.e., when children start going to school?

\section{The Triglossia in the UAE}

The is extensive sociolinguistic literature on Arabic diglossia [21,22], that is, the use of two languages under different conditions within a community, often by the same speakers. The term is usually applied to languages with distinct formal and informal (colloquial) varieties. MSA (the formal variant) and at least one Arabic dialect (the informal variant) are found in all Arabic communities. According to Schiffman [23], the assignment of functions in a diglossic speech community is not 
based on the language per se, but on the "linguistic culture" of this community. By linguistic culture, Schiffman [23] refers to "behaviors, beliefs, myths, attitudes, and historical circumstances associated with a particular language" (p. 215).

In the United Arab Emirates (UAE), however, this diversity is even more complex, as there are three languages that share prominence: Emirati dialect (L1), MSA (L2) and English (L2). The recent change from instruction at school exclusively in MSA to instruction mostly in English with some MSA and may lead to language shift, a phenomenon which has been widely discussed in the literature within the field of language policy and planning, as languages from powerful nations have threatened indigenous languages throughout the world.

English plays an important role in the Emirates nowadays. We will discuss three factors related to language shift proposed by Fasold [20]: population and migration trends, schooling and prestige factors. The new policy initiatives put Arabic and English on relatively equal footing [11,24,25]. Regarding the population, Emiratis account for only $10 \%$; they live among expatriate workers coming from partly Anglophone countries such as India, Sri Lanka and the Philippines, and majority English-speaking countries such as the United Kingdom and the USA. As such, English has become a lingua franca on 'all levels of society' [26]. With reference to education, private schooling in the Gulf is synonymous with an emphasis on English, which brings about better career prospects and higher social status. Many studies and reports have shown a preference among parents in the UAE of sending their children to private schools where the level of English curriculum is higher [11,27-29]. These issues of social status and career prospects are directly related to the third component which contributes to language shift, i.e., language prestige. Nowadays, English proficiency is a determining factor in the admission or rejection of Emirati students to college due to language admission tests, such as the IELTS [11]. In order to enter the three most prominent federal universities in the UAE, English proficiency, and not Arabic, is assessed. Although these federal universities require a 5.0 in IELTS, other foreign universities require 6.5 to 7.5. Students, therefore, focus on English proficiency, to the detriment of their Arabic literacy. Moreover, MSA is not ingrained early enough for young Arabs to become fully attached to it, or to attain the ability to gain fluency in reading or writing it [5]. The problem is clearly stated in the literature and in the many newspaper articles that have lamented the poor state of Arabic in the UAE [26,28-30]. This is not surprising, since subjects such as engineering, business, architecture and the sciences are all taught in English, while Arabic is consigned to the home or used in discussions about family, religion and other prosaic matters [18,31-33]. The focus on English has also impacted Arabic teachers, as English teachers have gained more social prestige [19,34]. In fact, Arabic teachers also complain that they are paid less and feel they have little support compared to English instructors [19,35]. For example, while there are many workshops for the professional development of English teachers in the UAE, this is not the case for Arabic teachers.

\section{Alramsa (the Dialect Spoken in the UAE) in Schools}

Arabic dialects are not present in textbooks in the UAE or in any other Arab country. In the UAE, all textbooks are either in MSA or English in public schools. Nevertheless, MSA is not students' L1 [12], but rather, their L2, introduced only in primary school. Alramsa is children's L1 in the UAE. Moreover, we have to keep in mind that teachers in the Emirates are mostly Arabic speakers from other countries, mainly from Egypt, but also from Palestine and Jordan [11]. For this reason, the use of Emirati Arabic by teachers is limited; the Emirati dialect is, however, used among Emirati students to communicate with their parents friends and even with their teachers at school, as we found in our study (see Appendix A).

\section{Publishing in Alramsa}

Thanks to the Alramsa Institute and its founders, Ms. Hanan Al-Fardan and Mr. Abdulla Alkaabi, more than 20 books have been published in the Emirati dialect, most of which are textbooks for expats and even for Emiratis who want to dive into their own dialect [36]. Alramsa is an institute specializing 
in teaching the Emirati dialect. There are also books for entertainment, including the 2019 publication of The Little Prince, which was used as the basis of this study. The Emirati version of The Little Prince was translated by Mr. Abdulla Alkaabi, who also owns the Emirati publishing house, Dragon Publishing, which has a collection of books in trilingual version: Emirati Arabic, MSA and English. It is important to note that the Arab world has a bias against publications in any Arab dialect, so the Alramsa Institute and Dragon Publishing are a breakthrough in Arab society.

\section{Methods}

The participants in this study were 25 Emirati parents and 25 children whose age ranged from 8 to 11 , all of whom were primary school students. Of the interviewed students, 21 go to private schools. The children answered an eight-question, open-ended questionnaire (see Appendix A), while the parents completed a questionnaire comprising 15 open-ended items (see Appendix B). Both parents and children were asked to read chapter XXI of the book The Little Prince (see Appendix C). One version was in MSA and the other in Alramsa (Emirati dialect).

\section{Lexical and Grammatical Differences in the MSA and the Emirati Dialect Version in The Little Prince}

We will analyze grammatical and lexical differences in chapter XXI of The Little Prince (see Appendix B). This chapter was read by primary students and parents just before they were interviewed. We can separate lexical differences into two groups: phonological differences and words that are totally different in the Alramsa dialect, compared to MSA. We will start by analyzing the first paragraph:

"It was then that the fox appeared."

"Good morning", said the fox."

The only parts that coincide in both versions in these two sentences are "said the fox" (qal altha3lib/قالالثعلب). "It was then" is expressed in MSA by a very formal expression anathaka (آنذاك); this expression in MSA, however, is not used in any Arabic dialect. The Emirati version simplifies it by using fi hay allahitha (في هاي اللحظة), which literally means "at that moment". The Alramsa version makes uses of simple words which are shared both in MSA and in the dialect, except for the word hay (هاي), which is a dialectal simplified version of the MSA word hathihi (هذه). The fox goes on with the phrase "good morning", which is translated into MSA by the expression sabah alkhair (صباح الخير(n)), which literally means "wake up in goodness". This expression is also used and understood in all dialects. Nevertheless, the dialectal version employs an exclusively Emirati way of greeting in the morning: sabahak allah bialkhair (احك ألله بالخير), which literally means "May God wake you up in goodness". The MSA version opted to maintain the original translation in order to answer this greeting: "the little prince answered politely "good morning" (sabah alkhair); however, it is rather unusual to answer sabah alkhair by repeating the same expression; the most common answer is sabah alnoor (صباح النور, meaning "wake up in light"). The Emirati translation was loyal to the Arabic usage, and even added more charm to the answer: Sabah alnoor wa alsooroor! (صباحالنور والسرور), which means "wake up in light and in pleasure". By adding this Emirati flavor, not only is the translator more loyal to real Arabic structures, but also, he brings kids and the characters closer, as these expressions are much more affectionate and are present and active in Emirati children's vocabulary.

The following line reveals an enormous grammatical difference between MSA and all Arabic dialects. No dialect uses the past tense lam + present tense, which is equivalent to didn't + infinitive in English; instead, the dialects use the form $m a+$ simple past, which also exists in MSA; nevertheless the version in Emirati used a very common way to report in the simple present, which brings the actions to the here and now of the listeners. While the formal translation of the MSA for he didn't see anything is lam yara shayanis (مايرَ شيئا'), it became, in the Emirati version, wama yashuf had (مايشوف حد), which means "he doesn't see anyone". The verb for "see" $\left(r a^{\prime} a\right)$ in MSA is never used in any Arabic dialect; rather, the verb shafa is used. 
The Emirati translation is also much more active in changing the original word order and making the text easier more comprehensible for children. In contrast, MSA keeps the original order: "I'm here," the voice said, "under the apple tree." Abdulla Alkaabi smartly changed the order here, and made it more authentically spoken: "He listened to a voice that said: I am here, look under the apple tree". The words here and tree in the MSA version are respectively huna (هنا) and shajara (هجرة), and Abdulla Alkaabi used the Emirati words huni (هنيه) and shayra (شيرة) in his version.

The following line is completely different in both versions. In order to express the sentences "Who are you?" the little prince asked, (and added) "You're very pretty...", the MSA kept the same order and used words which are uncommon to dialects, i.e., "man anta?", saalt Alamir Alsaghir wa adaaf

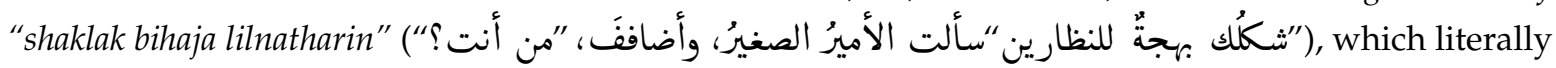
means: "“Who are you?" asked the little prince and added "your look is a delight to the lookers"”. It sounds very poetic; however, it is extraordinarily complex for children to understand. The Emirati version chose the direct speech: Qaal Alamir Alsaghir: man inta? Inta waid helu! (قال الأمير ألصغير: منو إنته ؟ إنته وايدحلو (مhich literally means: The little prince said: "Who are you? You are really pretty!" The word waid (وايد) is a khaleeji (Khaleeji refers to Arabian Gulf countries; not only the Emirates, but also Doha, Oman and Bahrain use the word waid) way of saying "very much, a lot"; the MSA equivalent word is kathir (كثير). The only remark regarding Alkaabi's translation concerns the spelling of the Arabic pronoun anta (meaning you, in the singular form), which is spelled أنت اin MSA. The same spelling could have been maintained without compromising children's understanding and as a way to unite MSA and dialect to some extent. Then, we would have iإنَإlinta instead of The problem with the latter is that the Arabic letter sattached to the end of a verb or a noun means "him", even in Emirati Arabic. Both spellings have the same pronunciation in Emirati dialect, but the first one (إنتَ) is the one that children will find in their textbooks in MSA. Therefore, besides teaching the dialect, the translator would be reinforcing the MSA, which is required at school.

When the little prince says: "I am very sad", the MSA book translates as ana fi muntaha ash-shaqaa' (أنا في متهىى الشقاءI'II am in extreme desolation”), while the Emirati translates ana waid hazin (أنا وايدحزين), meaning “I am really sad”. Again, we see Alkaabi's proclivity to make simple and authentic Emirati sentences.

Continuing the chapter, we have the sentence: "I can't play with you," the fox said. "I'm not tamed." The MSA version uses the verb astati3/أستطيع, meaning "can", which is only used in MSA, while the Emirati version employs the verb aqdar/أقدر/, which is used in most dialects and is also a synonym of astati3 in MSA. We believe that, as the book The Little Prince is read by many children, the MSA version could have employed synonyms that are present in dialects; this would facilitate reading and make it more pleasant for children, as it would be closer to their spoken language.

The chapter goes on with the answer "Ah! Excuse me," said the little prince." In the MSA version, we encounter an even more polite sentence than the original in French: ah! I3zrni min faDlik/oi! اعذزني من فضلك , which translates as "ah! Pardon me please, said the little prince." The little prince

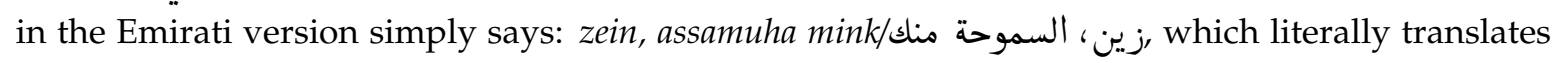
into "okay, excuse me" We have a much more colloquial little prince whose language is closer to the Emirati lexicon. The conversation follows: "You're not from around here," the fox said. "What are you looking for?" is translated in MSA as wa anta la ta3ish huna, literally meaning "and you do not live here"; this was simplified in the Emirati version to inta mob min huni, sah?, literally meaning: "You are not from here, right?". The verb "to look for" in MSA, abhath 3n, is substituted for the Emirati verb عن 3n أدور عن ناس/. Note that here, the translator mixed MSA by using the preposition $3 n$ nas 
and the Emirati verb Adawar ("I look for"); this verb in the Emirati dialect is followed by 3la على instead of $3 n$ عن.

When the fox says that "People raise chickens. Are you looking for chickens?", the MSA employs the word dejaj for chicken, substituted by the authentic Emirati variant deyay in the dialect version. The answer: "No," said the little prince, "I'm looking for friends." is translated in MSA by la, abhath $3 n$ Asdiqa', while the dialectal version is again loyal to its verb adawar and the word asdiqa'/أصدقاءal(friends) is replaced with a colloquial Emirati word, rabi3/ربع.

Next, when the little prince asks: "What does tamed mean?", it is important to highlight that no dialect uses the MSA word "MA/ما/ for the interrogative word "what"; the dialects use shoo (شو) in the Levantine and Khaleeji dialects, shnoo (شنو ) in the Darija dialect (Morocco, Algeria and Tunisia), and ee (إي ) in Egyptian Arabic.

The translation into MSA could have opted for a simpler way to answer "it means to create ties". It was literally translated as "its meaning is to establish relationships" (m3nah iqama 3lai'q/معناه إقامة علائق) (علاقة (slaqua) however the word for relationship has a very widely used regular

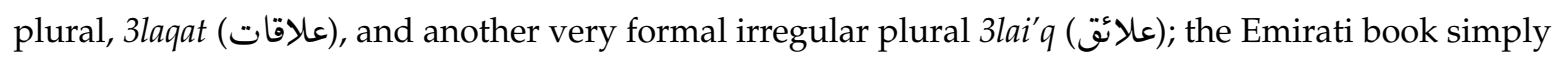
reads "its meaning is to tie relationships" (m3nah rabaT 3laqat/معناه ربط علاقات); however, here, the word "relationships" is in its most widely used, regular form.

This friendly and close approach in the Emirati translation runs through the whole book, while the MSA opts for a very formal and more distant translation. This distancing in the MSA version may be the reason why $92 \%$ of the children in this research were more interested in reading the Emirati version (L1); this is in accordance with Al-hussien and Belhiah's [17] research, which revealed that $85 \%$ prefer to read in English rather than in Modern Standard Arabic.

To summarize this section, we would like to present a table with lexical and grammatical differences in both translations.

Let us start with lexical differences, which can be divided into phonological differences and words which are completely different in both variants. Below are the main phonological differences in chapter XXI:

By observing Table 1, we should bear in mind that the children in our study ( 8 to 11 years of age) are in primary school, and that books in dialect are helpful for young readers learning to decipher print. However, if what is printed is not what the children are used to saying and hearing, then there is a distancing from the child's spoken dialect (L1). The linguistic distance between MSA and the child's spoken dialect has been found to interfere directly and persistently with the acquisition of language, metalinguistic skills and reading in MSA among young Arabic native speaking children [12-15].

Table 1. Phonological and lexical differences between MSA and Emirati Dialect.

\begin{tabular}{cc}
\hline MSA & Emirati Dialect \\
\hline huna (here) & huni \\
\hline shajara (tree) & shayara \\
\hline anta (you) & inta \\
\hline dejaj (chicken) & deyay \\
\hline
\end{tabular}

As evidenced in Table 2, it may be hard for the beginning reader to understand these words without the help of an adult, as they are totally different from the child's L1. 
Table 2. Words that are completely different in the two versions.

\begin{tabular}{cc}
\hline MSA & Emirati Dialect \\
\hline kathir (very) & waid \\
\hline ma (what) & shoo \\
\hline Asdiqa & rabi3 \\
\hline
\end{tabular}

Finally, let us summarize some grammatical differences and different verbs found in chapter XXI:

As Table 3 shows, the negative and the simple past are expressed in different ways. Some verbs in MSA are also totally different from Emirati Dialect.

Table 3. Grammatical differences and different verbs in MSA and Emirati Dialect.

\begin{tabular}{cc}
\hline MSA & Emirati Dialect \\
\hline laysa (not) & mob \\
\hline $\begin{array}{cc}\text { lam }+ \text { present simple or } \\
\text { ma }+ \text { simple past (did not) }\end{array}$ & ma + simple past \\
\hline abhath 3n (look for) & adawar \\
\hline yara (he sees) & yashoof (he sees) \\
\hline astati3 (can) & aqdar \\
\hline
\end{tabular}

\section{Results and Discussion}

We will now analyze parents' and children's concerns regarding MSA, Emirati Dialect and English, as well as their preferences with regard to The Little Prince in MSA and in Emirati Dialect.

Let us firstly analyze parents' concerns regarding the use of Emirati Dialect and English.

As Figure 1 shows, Emirati Dialect is Emirati children's L1. All of the respondents reported speaking Emirati dialect with their kids. No parents spoke MSA with their children. Nevertheless, four parents admitted reading the Quran to their kids (MSA); however, there was no interaction in such readings, the children only listened to the holy book. All parents also acknowledged that their children talked to their friends exclusively in Emirati dialect; however, four of the kids, who went to international schools, also spoke in English with some foreign classmates. No children spoke MSA with their friends.

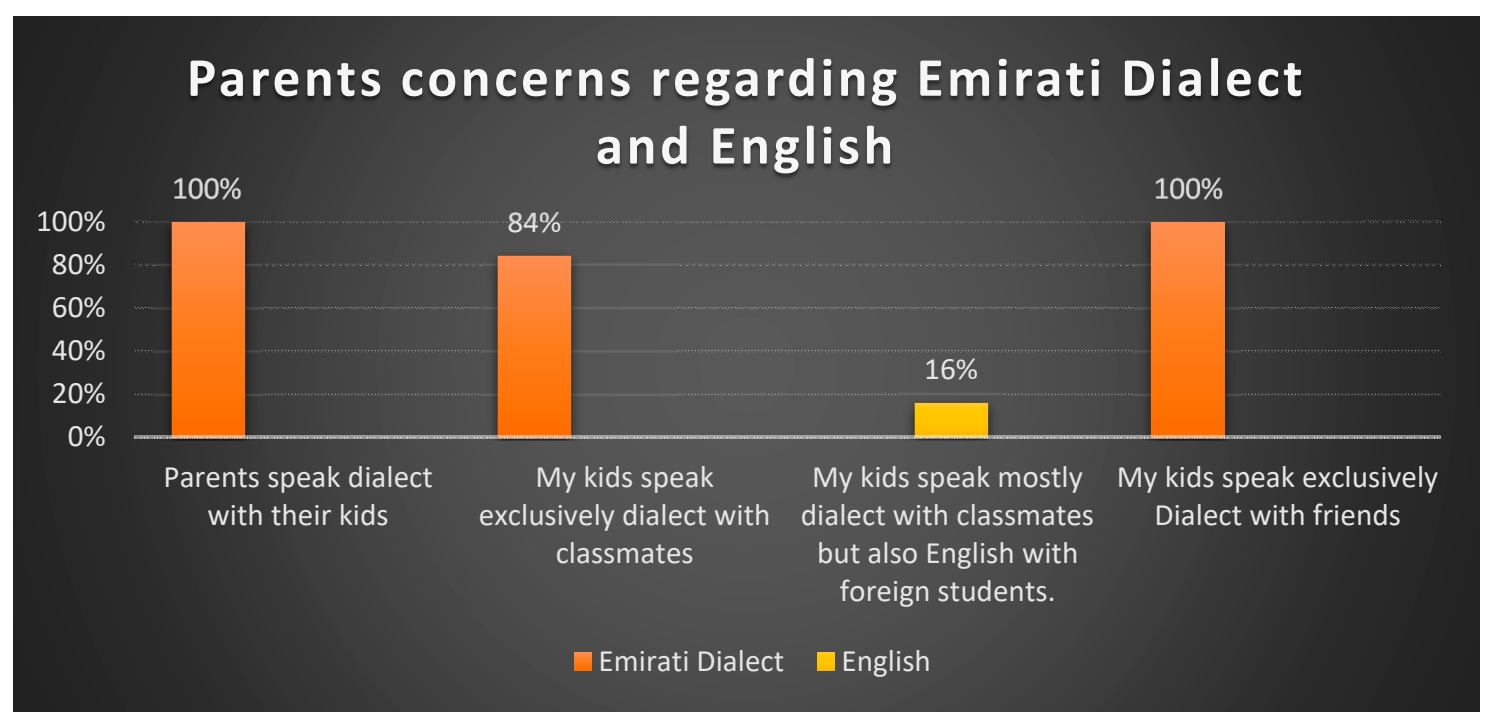

Figure 1. Parents concerns regarding MSA, Emirati Dialect and English. 
With regard to cartoons (question 3), parents reported that their children watched cartoons in English, MSA and in Dialect. This was interesting because four parents had to ask their kids in which language the cartoons were. Two parents straightforwardly answered: "I have no idea". Then they were kindly requested to ask their kids, one of whom answered that she watches most cartoons in English and another boy said he watched a potpourri of cartoons in the three versions. No children watched cartoons in just one language, and all of them watched at least one cartoon in English.

When asked if parents sing to their children, the answer was positive except for one father who said that the mother and the nanny did so. The nanny sang in English, as she was from the Philippines, and the mother mostly in Arabic but also in English. Only four parents sang a mix of songs in English and Arabic; the remaining $60 \%$ sang to or with their children exclusively in Arabic. The program "the Voice kids" was also mentioned by one parent, who reported that the kids were really into it and sang along with the "little singers". One parent noted his kids' passion for the Lebanese singer Majda el Roumi, as the father was also a huge fan, and affection for Majda's songs had rubbed off on his children.

As evidenced by Figure 2, all parents read the Quran to their kids from their birth, and even when they were inside the mother's womb. All of them agreed that such a practice helps children improve their MSA. Only seven parents still read stories to their kids. Another ten parents (40\%) reported doing so when they were younger. Also, 20\% of parents said that they read stories to their kids in English to help them at school, and two other parents said they would read whatever is available, but usually in MSA or English, as books in the dialect are rare. It was interesting that four parents reported reading in MSA but explaining difficult words in the dialect.

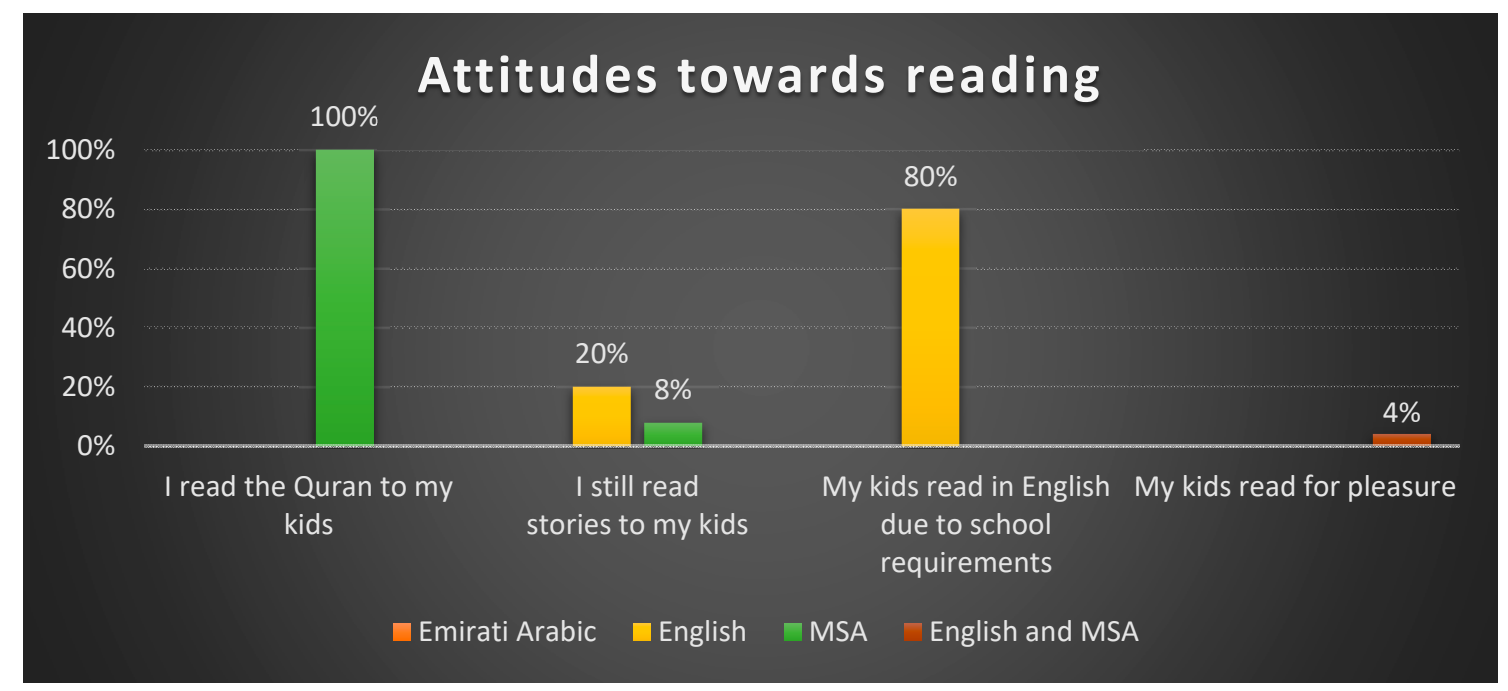

Figure 2. Emiratis Attitudes towards Reading.

Regarding languages the children read in (question 10), 80\% of parents reported that they read in English because these books are a requirement of the school. Only $4 \%$ reported that their kids read for pleasure.

Figure 3 shows the language instruction at school. Regarding the subjects that students attend in Arabic (question 14), the 21 students that go to private schools have all their subjects in English except for Arabic Language Studies and Islamic and Social Studies. (These two subjects have been compulsory in the UAE since 1999 for all Muslim students in private schools [37].) The remaining four students have all subjects taught in Arabic except for English language and science. Concerning question 14, Arabic teachers in private schools tend to speak MSA 90\% of the time, as books are all in Classic Arabic, and these teachers are in charge of teaching either the Arabic Language or Arab culture. A couple of parents reported that their kids were sometimes interrupted when speaking in the dialect and were asked to paraphrase using MSA. 


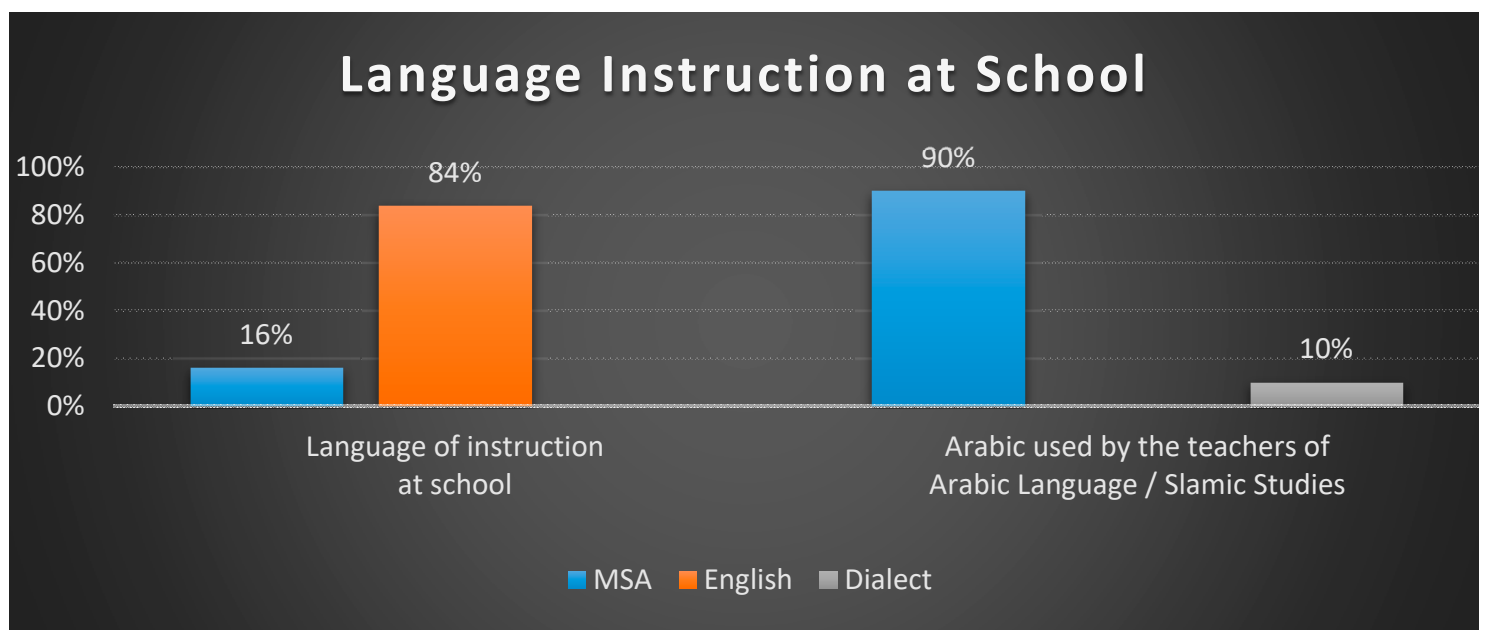

Figure 3. Language of Instruction at School.

As we can see in Figure 4, 56\% of the parents (14 parents) chose the MSA version for their kids, stating that this is the official language of the country and the language of the Quran. Also $32 \%$ of parents (eight participants) stated that kids have been listening to MSA since they were in the wombs of their mothers, when the parents recited the Quran, and such practice has been repeated daily since then. There were some negative remarks concerning the dialectal version: "this language is wrong for books", "we know this is not the correct way to write", "at school they have to learn Arabic, not the dialect, the dialect they learn at home". One parent went even further by reading the dialectal version and pointing out how it should be "we don't say huni in Arabic, we know it is huna, it is not deyay, it is dejaj, ... and I want my children to learn the right words." On the other hand, the remaining $44 \%$ who chose the Emirati Dialect version claimed that this would be easier for their kids to understand, or that this is the language they speak at home. It is important to note that $84 \%$ of parents said that both versions were important, as one represents the union, the religion and the formal language, and the other represents local culture and autochthonous identity.

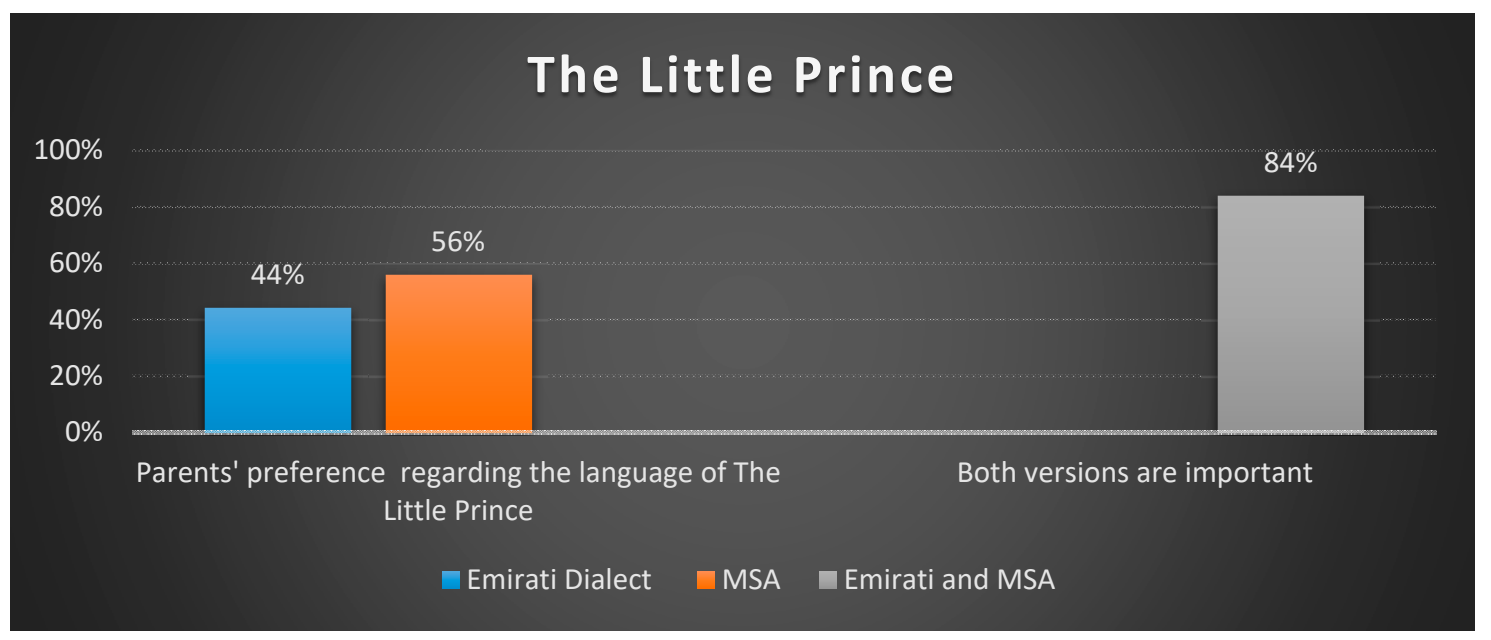

Figure 4. The Little Prince in MSA or Emirati Dialect.

\subsection{Suggestions Proposed by Parents}

In order to improve Arabic learning both at school and home, parents suggested the following: $60 \%$ of parents suggested more reading; One parent mentioned an activity carried out by the school which consists of reading a story and making a summary of it to the teacher who subsequently listens to and corrects it; Two parents suggested having more subjects in Arabic, noting that only two subjects 
in MSA is not enough: "There should be a balance between how it was in the past (all in Arabic) and how it is now (mostly in English)." Nevertheless, some parents said that what children learn at school and at home is enough, and no changes need to be made.

\subsection{Suggestions Proposed by the Study}

Reading books in the dialect can be complemented in the classroom with exercises of word matching, for instance, deyay ("chicken" in dialect) and dejaj ("chicken" in MSA), huni ("here" in dialect) and huna ("here" in MSA); after reading the book in the dialect, students can be given passages in MSA and guess the meaning of the formal words based on their knowledge of the dialectal version. Students could also be given two short passages, i.e., one in dialect and the other in MSA, and then compare both versions and discuss the similarities and differences. A final game could be introduced, for instance, a vocabulary race: Students could be divided into two groups; the teacher writes words in MSA on the board and when he/she says the word in the dialect, one child from each group has to run and touch the corresponding word on the board. The first child from either group who reaches the matching word first scores a point. The impact of a linguistic analysis of the distance between the Emirati spoken dialect and Standard Arabic was reported in the research of Saiegh-Haddad and Spolsky [38], which compared identical, cognate and unique words in quantifying the lexical distance between the two language varieties. This study showed that only $21.2 \%$ of the words in the spoken lexicon of five-year-old children were identical in both varieties, i.e., MSA and, in this case, Palestinian Arabic, whereas $40.6 \%$ were cognate words with different surface phonological forms, and $38.2 \%$ were unique to Palestinian Arabic and had no conventional spelling in Arabic.

As Figure 5 shows, $96 \%$ of the primary school students found it boring to communicate in MSA with their parents. Four children even said: "I don't communicate in Fusha, it is just to read books at school and the Quran" and "We need Fusha to watch television sometimes and to read books" (Although Fusha is the variety of standard Arabic in the Quran and early Islamic writings, and MSA is the standardized, literary Arabic that developed in the Arab world in the late 19th and early 20th centuries, native Arabic speakers use the term Fusha to differentiate any formal writing or speech from their dialects).

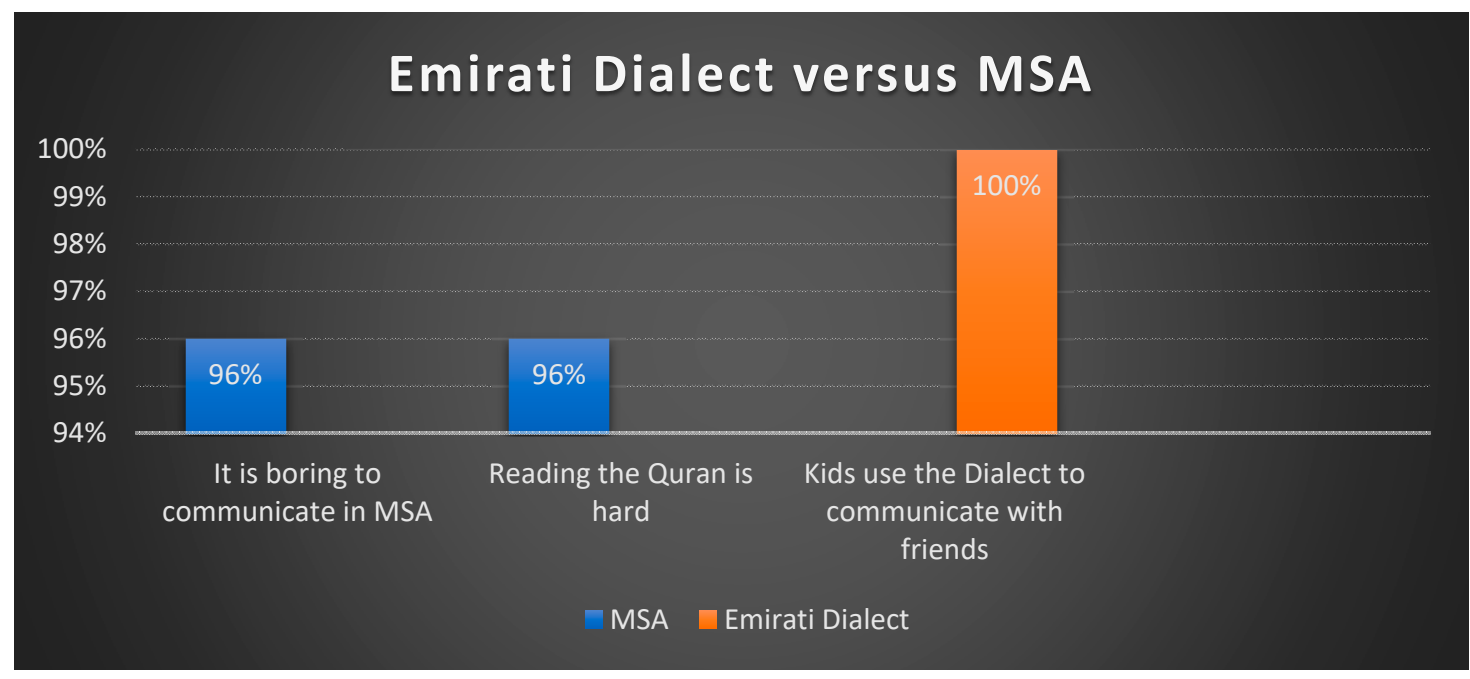

Figure 5. Children's feelings towards the Emirati Dialect and MSA.

When asked whether they felt bored using MSA at school (question 2), 72\% reported that they do not communicate in MSA; some students added that even some of their teachers do not communicate in MSA. Additionally, 28\% of the students said that it was difficult to communicate in MSA.

Question three was unanimously answered that students use only the dialect to communicate with their friends. 
Concerning the fourth question, $96 \%$ of the children opined that reading the Quran is hard, and many times, their parents explain some words to them. Only $4 \%$ said that the language in the Quran was okay as they read it on a daily basis.

As Figure 6 shows, $88 \%$ of the children preferred the Emirati dialect version of The Little Prince [39]. These children stated that this version was more authentic and easier to understand. Other kids expressed the same feeling using other words: "They speak normally, like us". A 10-year-old boy noted "he is a boy, a boy says dyay, not dejaj; dejaj would be a powerful old person speaking" (Dyay is the Emirati dialect word for "chicken"; the equivalent in MSA is dejaj. The child expressed the appropriateness of the vocabulary with the age of the character, as all children communicate in the dialect instead of MSA).

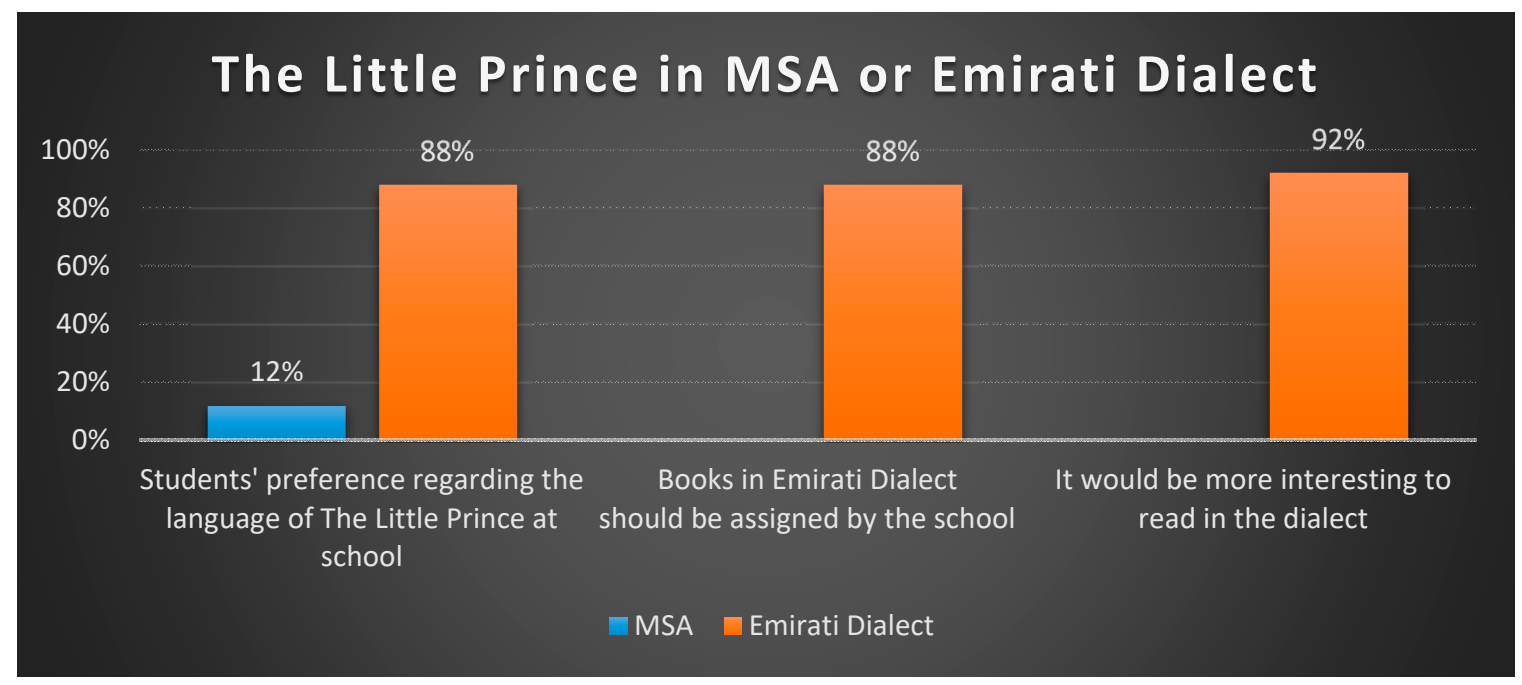

Figure 6. The Little Prince in MSA or Emirati Dialect.

While reading the beginning of the text in MSA [40] "It was then that the fox appeared", an eight-year-old boy did not understand the word anathak, which means "it was then", and asked his father in Emirati dialect: "what does anthak mean, dad?" The father paraphrased the word in Emirati dialect.

Concerning the assignment of books in Emirati dialect by the school, the same results as in the previous question were obtained: $88 \%$ of students believed that the school should assign books in dialect. Three students also mentioned that the school only assigns books in English. When asked if it would be interesting to read in the dialect, $92 \%$ of the children answered "yes!". It was surprising that four students said that they had never read in their dialect.

The final question inquired if their teachers speak in MSA or dialect. All the students answered that their teachers speak in the dialect, and that some teachers speak other dialects like Jordanian or Egyptian; only the Arabic Language teachers speak mostly or solely in MSA.

\section{Conclusions}

As evidenced by the literature, the new policy initiatives in the UAE put MSA and English on relatively equal footing $[11,24,25]$. Emiratis account for only $10 \%$ of the total population, and English has become a lingua franca on all levels of society [26]. With reference to school, private schooling in the Gulf is synonymous with more English, and many studies and reports have shown a preference among parents in the UAE for sending their children to private schools [11,27-29]. These factors are contributing to a language shift. With more English at school, students have less contact with MSA. The problem with the bilingual curriculum in the UAE is that some students are assigned many books in English, which are gradually superseding books in MSA. The UAE Ministry of Education has to be 
aware that the overuse of English in schools may, after some decades, create a generation of students that are not able to proficiently read and write in their own language.

Although this study is not in keeping with that of Kennetz and Carroll [41], who found that publishing companies publish books exclusively in MSA, we agree that the majority of Arabic books are published in MSA. The Little Prince in Emirati Arabic, however, is just one of many exceptions. Written Emirati dialect is slowly gaining ground in the UAE, as we confirmed in an interview with the director of Dragon Publisher UAE, Mr. Abdulla Alkaabi, who has published a collection of books in trilingual versions, i.e., Emirati Dialect, English and MSA.

In light of our results, most parents (84\%) believed that the dialect and MSA are important, and although 56\% believed that MSA has to be the only Arabic source at school, these figures show a new trend of acceptance and legitimacy of the dialect as a tool for literacy.

It was founds that $92 \%$ of the interviewed children were more interested in reading The Little Prince in their own dialect, and $88 \%$ also chose the dialectal version for use at school, i.e., students prefer the language they speak daily, and they are confident with. The dialect is also the main language of students and teachers, except for teachers that teach English or subjects in English. At school, MSA is restricted to the language written in the textbooks and in the Quran. For these reasons, we believe that having books in dialect could facilitate reading. Reading in MSA is almost like reading in a foreign language for them [12]. We should not view books in dialect as a threat to MSA, but as a bridge to it, especially in the first years of primary school. Therefore, we recommend reading books in the dialect in the first years of primary school. Our study found that MSA is problematic for children, as it possesses many very formal words, that sometimes are difficult even for native Arabic speakers, while the dialectal version is closer to the kids' vocabulary and has a simpler grammar. The perceived linguistic distancing in the MSA version may be the main reason why $92 \%$ of the children in this research were more interested in reading the Emirati version (L1). Reading books in the dialect is helpful not only for young readers learning to decipher print, but also for parents who want to engage with their children in reading activities. Such activities, such as storybook reading for children, even when performed in the spoken dialect, will enhance the child's linguistic and cognitive skills, including their vocabulary, comprehension, inferencing, reasoning, world knowledge and many other abilities and skills that develop first and more effectively in the language that children master [12,13].

This present research has a number of limitations, and makes the following proposals to improve them in future research. The first limitation regards the number of participants. In future studies, an increased number of participants would increase the strength of the results, and therefore, increase the generalizability of the findings. Another suggestion would be to apply the suggestions in this study into an experiment, i.e., the use of books in an Arabic Dialect to promote reading in the classroom, using a rigorous research design (tools, analyses, etc.) to produce scientifically sound conclusions that may be implemented in the teaching of Arabic throughout the Arabic speaking world. Such an experiment with students who read in dialect (L1) may be then contrasted with students' preference to read in English or in dialect. And finally, the figures obtained could be compared with those in Al-hussien and Belhiah's [17] research, which revealed that $85 \%$ of children prefer to read in English rather than MSA. If this preference for English decreased, then having books available in the dialect (L1) could be used to mitigate the language shift which is occurring in the UAE.

In conclusion, our study revealed that $92 \%$ of the interviewed children were more interested in reading the dialectal than the MSA version; the majority of parents $(84 \%)$ agreed that both the spoken dialect and MSA were important for their children, even though about half of them $(56 \%)$ believed that Standard Arabic should be the only language of the written resources used at school. These findings reveal a trend in the Arabic speaking world of increasing legitimacy and acceptance of adding a literacy function to the spoken dialect, as well as a change in the perceptions of parents regarding the importance of dialects as a constituent of children's linguistic repertoires. Our study is in keeping those of Saiegh-Haddad [12-14,38], which revealed that the linguistic distance between MSA and the child's spoken dialect was found to directly and consistently interfere with the acquisition of 
language, metalinguistic skills and reading in MSA among young Arabic native speaking children. This may be one of the reasons why Al-Issa and Dahan [18], Al-hussien and Belhiah [17], and Al-Issa [14] reported that $96 \%$ of parents affirmed that their children prefer to read in English than in MSA (L2).

Our research, which inquired if children would prefer to read books in the Emirati dialect, as it is their L1, or in MSA, revealed that $92 \%$ of the children found the Emirati version more interesting and that $88 \%$ would like to see the dialectal version in use at school.

In order to minimize the aversion to Arabic literature, as well as to mitigate the language shift to English which is occurring in the UAE, reading in dialect might be an appropriate solution. In addition, it would serve as an important bridge to Arabic literature, as we would have more motivated readers, readers who would understand books and not see them as being in a foreign language. A gradual introduction of MSA into books written in dialect would likely ease the transition from dialect (L1) to MSA (L2).

Funding: This research received no external funding.

Conflicts of Interest: The author declares no conflict of interest.

\section{Appendix A. Questionnaire for Children, English Version}

1. Do you find it difficult or boring to communicate in MSA with your parents?

2. Do you find it difficult or boring to communicate in MSA at school?

3. What language do you use to communicate with your friends?

4. What do you think about the language in the Quran, is it difficult or do your parents explain it to you?

5. Read this short passage from the book The Little Prince, in MSA and in Colloquial Arabic, which one would you choose to read at school? (chapter XXI, see below)

6. Do you think your school should assign books in Colloquial Arabic?

7. Would it be more interesting to read in Colloquial Arabic?

8. Do teachers at school speak in MSA or in Colloquial Arabic?

\section{Appendix B. Questionnaire for Parents English Version}

1. Do you communicate with your child in Arabic?

2. Do you use MSA or Colloquial Arabic with him/her? Does your child find it difficult or feel bored when you use MSA?

3. Does your child watch TV programs/cartoons in Arabic? Are these programs in MSA or colloquial Arabic?

4. What language does your child use to communicate with his/her friends?

5. Do you sing to/with your child? In what language are the songs?

6. Do you read the Quran to your child?

7. Do you think reading the Quran contributes to the development of your child's MSA proficiency?

8. Do you read other books/stories to your child?

9. Are these books in MSA or in Colloquial Arabic?

10. Does your child usually read books? In which language are they?

11. Read this short passage from the book the little prince, in MSA and in Colloquial Arabic, which one would you choose for your child and why?

12. Do you think schools should assign books in Colloquial Arabic to primary students or only books in MSA?

13. What schools subjects does your child have in English and in Arabic?

14. Do teachers at school speak in MSA or in Colloquial Arabic?

15. What are the suggestions to encourage Arabic language in the home and at school? 


\section{Appendix C. Chapter Twenty One (English Version)}

It was then that the fox appeared.

"Good morning", said the fox.

"Good morning", the little prince answered politely, though when he turned around he saw nothing.

"I'm here", the voice said, "under the apple tree."

"Who are you?" the little prince asked. "You're very pretty..."

"I'm a fox", the fox said.

"Come and play with me", the little prince proposed. "I'm feeling so sad."

"I can't play with you", the fox said. "I'm not tamed."

"Ah! Excuse me", said the little prince. But upon reflection he added, "What does tamed mean?"

"You're not from around here", the fox said. "What are you looking for?"

"I'm looking for people," said the little prince. "What does tamed mean?"

"People", said the fox, "have guns and they hunt. It's quite troublesome. And they also raise chickens. That's the only interesting thing about them. Are you looking for chickens?"

"No" said the little prince, "I'm looking for friends. What does tamed mean?"

"It's something that's been too often neglected. It means, to create ties..."

"To create ties?"

\section{References}

1. Brook, D. A History of Future Cities. New York; W.W. Norton \& Company, Inc.: New York, NY, USA, 2013.

2. United Arab Emirates Demography and Statistics through a Magnifying Glass. Available online: https: //tgmresearch.com/uae-population-and-demographics.html (accessed on 10 October 2020).

3. United Arab Emirates Population Statistics. 2020. Available online: https://www.globalmediainsight.com/ blog/uae-population-statistics/ (accessed on 10 October 2020).

4. Carroll, K.S.; Al Kahwaji, B.; Litz, D. Triglossia and promoting Arabic literacy in the United Arab Emirates. Lang. Cult. Curric. 2017, 30, 317-332. [CrossRef]

5. Findlow, S. Higher education and linguistic dualism in the Arab Gulf. Br. J. Soc. Educ. 2006, 27, 19-36. [CrossRef]

6. Why Emiratis Pick Private Schools. Available online: https://gulfnews.com/uae/education/why-emiratispick-private-schools-1.1324786 (accessed on 10 October 2020).

7. Emiratis Choosing Private Education over Public. Available online: https://www.thenationalnews.com/ uae/emiratis-choosing-private-education-over-public-1.374302\#: \{\}:text=DUBAI\%20\%2F\%2F\%20More\% 20than $\% 20$ half,according $\% 20$ to $\% 20 \mathrm{a} \% 20$ new $\% 20$ study (accessed on 10 October 2020).

8. FNC Debates Why Emirati Students Are Turning to Private Schools. Available online: https://gulfnews.com/uae/ fnc-debates-why-emirati-students-are-turning-to-private-schools-1.68861670 (accessed on 10 October 2020).

9. Majority of Dubai's Emirati Children Attend Private Schools. Available online: https://www.edarabia.com/ 21227/majority-of-dubais-emirati-children-attend-private-schools/ (accessed on 10 October 2020).

10. Solloway, A.J. English-Medium Instruction in Higher Education in the United Arab Emirates: The Perspectives of Students; University of Exeter: Exeter, UK, 2016.

11. Al-Hussein, M.; Gitsaki, C. Foreign Language Learning Policy in the United Arab Emirates: Local and Global Agents of Change. In Journal (Un)intended Language Planning in a Globalising World; De Gruyter: Berlin, Germany, 2017. [CrossRef]

12. Saiegh-Haddad, E. Linguistic Distance and initial reading acquisition: The case of Arabic diglossia. Appl. Psycholinguist. 2003, 24, 431-451. [CrossRef]

13. Saiegh-Haddad, E. The impact of phonemic and lexical distance on the phonological analysis of words and pseudowords in a diglossic context. Appl. Psycholinguist. 2004, 25, 495-512. [CrossRef]

14. Saiegh-Haddad, E. Learning to read in Arabic. In Reading Acquisition across Languages and Writing Systems: An International Handbook; Verhoeven, L., Perfetti, C., Eds.; Cambridge University Press: Cambridge, UK, 2017; pp. 127-154. 
15. Saiegh-Haddad, E.; Haj, L. Does phonological distance impact quality of phonological representations? Evidence from Arabic diglossia. J. Child Lang. 2018, 38, 297-315.

16. Siemund, P.; Al-Issa, A.; Leimgruber, J.R.E. Multilingualism and the Role of English in the United Arab Emirates. World Englishes; Wiley Online Library: Hoboken, NJ, USA, 2020; pp. 1-14. Available online: https://www.researchgate. net/publication/341099698_Multilingualism_and_the_role_of_English_in_the_United_Arab_Emirates (accessed on 10 October 2020). [CrossRef]

17. Al-hussien, A.; Belhiah, H. Instruction through the English Medium and its Impact on Arab Identity. Arab World Engl. J. 2016, 7, 2.

18. Al-Issa, A.; Dahan, L. Global English and Arabic: Issues of Language Culture, and Identity. In Contemporary Studies in Descriptive Linguistics; Peter Lang UK: Berm, Switzerland, 2011; Volume 31.

19. Al-Issa, A. English as a Medium of Instruction and the Endangerment of Arabic Literacy: The case of the United Arab Emirates. Arab World Engl. J. 2017, 8, 3-17. [CrossRef]

20. Fasold, R.W. Sociolinguistics of Society; Blackwell: Cambridge, MA, USA, 1993.

21. Ferguson, C. Diglossia. Word 1959, 15, 325-340. [CrossRef]

22. Wardhaugh, R.; Fuller, J. An Introduction to Sociolinguistics, 7th ed.; John Wiley \& Sons, Inc.: Hoboken, NJ, USA, 2015.

23. Schiffman, H.F. Diglossia as a sociolinguistic situation. In The Handbook of Sociolinguistics; Coulmas, F., Ed.; Blackwell: Cornwall, UK, 1997; pp. 205-216.

24. Carroll, K.S.; Combs, M.C. Bilingual education in a multilingual world. In Routledge Handbook of English Language Teaching; Graham, S.H., Ed.; Routledge: New York, NY, USA, 2016; pp. 191-205.

25. Cook, W.R.A. More vision than renaissance: Arabic as a language of science in the UAE. Lang. Policy 2017, 16, 385-406. [CrossRef]

26. Randall, M.; Samimi, M. The Status of English in Dubai. Engl. Today 2010, 26, 43-50. [CrossRef]

27. KHDA. Private Schools in Dubai: The Evolving Government and Private School Relationship. 2011. Available online: https:/www.khda.gov.ae/CMS/WebParts/TextEditor/Documents/IPSEF\%20paper.pdf (accessed on 28 November 2020).

28. Kenaid, K. In Search of Good Education: Why Emirati Parents Choose Private Schools in Dubai; Knowledge and Human Development Authority: Dubai, UAE, 2011.

29. Pennington, R. Emirati Parents Increasingly Turning to Private Schools. The National. 2015. Available online: http://www.thenational.ae/uae/education/emirati-parents-increasingly-turning-to-private-schools (accessed on 20 November 2020).

30. Al Najami, S. Bilingual Education Hangs in the Balance for Schools. The Nation: Education. 18 October 2007. Available online: https:/gulfnews.com/uae/education/bilingual-education-hangs-in-the-balance-for-schools1.207122 (accessed on 18 November 2020).

31. Al-Issa, A. Arabic Must be the Focus in Pursuit of 'True' Bilingualism. The National. 9 February 2012. Available online: https://www.thenationalnews.com/arabic-must-be-the-focus-in-pursuit-of-true-bilingualism-1. 454642 (accessed on 25 November 2020).

32. Dahan, L. Global English and Arabic: Which is the Protagonist in a Globalized Setting? Arab World Engl. J. 2013, 4, 45-51.

33. English as a Medium of Instruction and the Endangerment of Arabic Literacy: The Case of the United Arab Emirates. Available online: https://www.researchgate.net/publication/320013365_English_As_ a_Medium_of_Instruction_and_the_Endangerment_of_Arabic_literacy_The_Case_of_the_United_ Arab_Emirates (accessed on 28 November 2020).

34. Bassiouney, R. Language and Identity in Modern Egypt; Edinburgh University Press: Edinburgh, UK, 2014.

35. Badry, F.; Willoughby, J. Higher Education Revolutions in the Gulf: Globalization and Institutional Viability; Routledge: Abingdon, UK, 2016.

36. Al Fardan, H.; Al Abdulla, K. Spoken Emirati Phrase-Book; Poetry Academy: Abu Dhabi, UAE, 2014.

37. New Private School Rules Require Teaching of Islamic Studies. Available online: https://gulfnews.com/uae/ new-private-school-rules-require-teaching-of-islamic-studies-1.420954 (accessed on 10 October 2020).

38. Saiegh-Haddad, E.; Spolsky, B. Acquiring literacy in a diglossic context: Problems and prospects. In Handbook of Arabic Literacy: Insights and Perspectives; Saiegh-Haddad, E., Joshi, M., Eds.; Springer: Dordrecht, The Netherlands, 2014; pp. 225-240. 
39. Saint-Exupéry, A. The Little Prince (El Ameer El Saghir); Bilingual ed. Emirati and English; Dragon Publishing: Abu Dhabi, UAE, 2019.

40. Saint-Exupéry, A. El Ameer El Saghir; Schiler Hans Verlag: Berlin, Germany, 2016.

41. Kennetz, K.; Carroll, K. Language threat in the United Arab Emirates? Unpacking domains of language use. Int. J. Sociol. Lang. 2018, 2018, 165-184. [CrossRef]

Publisher's Note: MDPI stays neutral with regard to jurisdictional claims in published maps and institutional affiliations.

(C) 2020 by the author. Licensee MDPI, Basel, Switzerland. This article is an open access article distributed under the terms and conditions of the Creative Commons Attribution (CC BY) license (http://creativecommons.org/licenses/by/4.0/). 